\title{
Teachers' expertise in feedback application adapted to the phases of the learning process
}

\section{Eva Christophel*, Robert Gaschler and Wolfgang Schnotz}

Department of Psychology, Universität Koblenz-Landau, Landau, Germany

*Correspondence: christophel@uni-landau.de

Edited by:

Michael H. Connors, Macquarie University, Australia

Reviewed by:

Craig Speelman, Edith Cowan University, Australia

Michael H. Connors, Macquarie University, Australia

Keywords: teacher expertise, motivational phases, learning phases, feedback, curriculum scripts

\section{BUILDING BETTER BRAINS-SCHOOL DAY BY SCHOOL DAY}

In this essay we highlight feedback application as a domain to study the knowledge and abilities involved in the construct of teachers' expertise. One approach to advance the discussion in a field of research such as expertise acquisition generally is to combine (a) analysis of complex natural phenomena by division into hypothetical simple building blocks, with (b) the synthesis of complex phenomena based on known simple building blocks (e.g., Braitenberg, 1984; Gaschler et al., 2012). For instance, (a) knowledge representations such as chunks have been hypothesized to underlie chess expertise and (b) this analysis in turn was supported by a computer-run expert system based on chunks (cf. Lane et al., 2001; Guida et al., 2012). Gobet et al. (2014) summarize research on expert knowledge as well as the Einstellung effect (e.g., missing a to spot an efficient procedure, because a wellknown one is available; cf. Bilalić et al., 2010), and neuro-interventions targeting it. They conclude with the desideratum to build better brains-brains that can take full advantage of the power of hypothesis-driven cognition while being safeguarded against cognitive illusions and the Einstellung effect.

In the current article we argue that building better brains is (an admittedly to-be-optimized) everyday practice, rather than a thought experiment. Like Gobet et al. (2014) we ask how creativity can be fostered by gaining control over prior knowledge so that it can be flexibly used or blocked at demand (cf. Bilalić et al.,
2008). Teacher education in universities delivers quasi-experimental conditions for studying how expertise on learning can be acquired and applied best. In particular, concepts of motivation and action control relevant in robotics and psychology seem promising in order to capture and structure the gist of teacher expertise.

\section{BECOMING EXPERTS IN FACILITATING KNOWLEDGE ACOUISITION}

While expertise is often studied in domains that yield only hundreds or thousands of experts, universities all over the world are taking efforts to continuously contribute to a large population of experts on knowledge acquisition. Based on theoretical input and years of practice, teachers should be experts for shaping school lessons such that knowledge acquisition is optimized (Bromme, 1997, 2008). Focusing on the demands placed by school lessons can help to obtain an overview on the skills teaching experts should have (Bromme, 2008). Teachers have to organize and maintain a structure of student and teacher activities. This includes the anticipation of students' inferences as well as disturbances of the social context of learning. Teachers need a broad and flexible knowledge base covering the subject, as well as a repertoire of instructional methods to stimulate students' learning activities for reaching instructional objectives. Like managers, teachers have to organize the timetable of each lesson to make sure that the time is mainly used for the subject matter. Shulman $(1986,1987)$ attributes to teaching experts a repertoire of content knowledge (e.g., diagnosis of task specific requirements), pedagogical content knowledge (e.g., how to present the subject matter content), and curricular knowledge. Leading to the appropriate generation and scheduling of feedback to the students, teaching experts should have a strong background in the philosophy of the subject (e.g., subject-related epistemic beliefs), diagnostic competences (e.g., judgment of students' abilities), and skills that allow them to juggle between studentrelated aspects of the learning situation as well as content-related aspects (Bromme, 2008). Teachers' instructional routines include categorical units called "curriculum scripts," in which subject-related and didactic-methodological aspects are linked. As a consequence of this integrated knowledge, most actions of experienced teachers proceed automatically (Blömeke et al., 2003). They are difficult to access via verbal protocols, because in the classroom or a face-to-face situation, verbalization of the teacher could reduce the learners' amount of cognitive resources and shift the learner's attention to the level of meta-task processes.

\section{FEEDBACK ALIGNED TO MOTIVATIONAL AND VOLITIONAL STATES OF ACTION REGULATION}

Learners face the challenge to acquire and employ self-regulation strategies in order to obtain educational outcomes (e.g., Lerner et al., 2001; Ley and Young, 2001). In order to scaffold learning through adaptive feedback, teachers need knowledge about the dynamics of learning processes and opportunities to apply feedback that takes motivational, cognitive 
and emotional aspects of learning into account. Apart from finding the appropriate frequency for feedback (Healy et al., 2014), we suggest consideration of the match of feedback type and action phase the learner is currently in Heckhausen and Gollwitzer (1987) have proposed distinguishing between motivational and volitional phases of action regulation. The distinction between motivational and volitional phases of action regulation has been used in two different ways to bridge the gap between analysis and synthesis highlighted by Braitenberg (1984). On the one hand, many architectures of artificial agents in robotics implement the distinction between a motivational phase (the agent is open to new information and ready to re-evaluate current preferences and plans) and a volitional phase (the agent is executing a plan and shielding itself from novel information that might lead to a re-evaluation of the plan currently executed; e.g., Visser and Burkhard, 2007). On the other hand, cycles of motivational and volitional phases are present in theories of the cyclical and recursive dynamic of learning in educational contexts (e.g., Zimmerman, 2000; Schmitz and Wiese, 2006).

According to Zimmerman (2000) as well as Schmitz and Wiese (2006), the learning process proceeds in three phases. (1) In the goal-setting phase, the learner chooses goals (e.g., appropriate tasks), plans actions or action steps and selects adequate strategies. (2) In the performance phase, the selected strategies have to be applied in order to complete the task. (3) In the self-reflection phase, the learner evaluates his/her learning outcome. Gollwitzer (1990) assumes that in each one of these phases the learners' attention is focused on specific information that helps him/her to accomplish the demands of the task. Taking the current focus of the learner into account, feedback can be better adapted with respect to effects on the learners' performance, mood and effort (Ley and Young, 2001; Narciss, 2004; Baadte and Schnotz, 2013).

Three types of feedback can be distinguished that align to the respective phases of the learning process. In the goal setting phase, the learner should receive goal-setting feedback that informs him/her about how realistic completion of the chosen task is according to his/her previous performances. In the performance phase, process-feedback offers information about specific task-inherent demands and error-related information. In the self-reflection phase, the learner should obtain appropriate outcome-feedback that informs him/her about the possible causes for success or failure and about the quality of his/her performance. In contrast, feedback is inappropriate if it does not take the learner's phase-specific mind-set into account and if it does not support the task completion but instead decreases the learner's amount of cognitive resources available for processing the relevant information (e.g., Sweller, 2005; see Christophel and Baadte, in press).

Matching feedback to the phasespecific requirements of the learning process might require flexible strategy changes and adaptation of routines to the specific content being taught, epistemic beliefs and motivational/volitional state diagnosed. Thus, adaptation and shifting skills seem at least as important as a large repertoire of strategies. This view is reflected in the notion of adaptive expertise advocated in education psychology (Verschaffel et al., 2009; Godau et al., 2014). In contrast to routine expertise (e.g., expertise that allows the expert to solve problems very efficiently and precisely), Hatano and Inagaki (1984) describe adaptive expertise as the potential to create new solutions and new problem solving procedures. Adaptive experts are "those who not only perform procedural skills efficiently but also understand the meaning of the skills and nature of their object" (p. 28). In contrast, "routine experts are outstanding in terms of speed, accuracy, and automaticity of performance, but lack flexibility and adaptability to new problems" (Hatano and Inagaki, 1984, p. 31). Verschaffel et al. (2009) have pointed out that flexibility can be defined as the "use of multiple strategies" while adaptivity includes "making appropriate strategy choices" (p. 338). This flexibility and adaptivity is necessary in order to support students' individualized learning processes with appropriate feedback. Thus, teachers need adaptive expertise which should include knowledge about the task specific requirements, the learner abilities, the cyclical and recursive dynamic of the learning process and the implications of this dynamic on motivational, cognitive and emotional levels. On the one hand, there are first formalized efforts to teach future teachers relevant motivational competencies (e.g., Rheinberg and Engeser, 2010). On the other hand, there are more cautious outlooks as well. According to Verschaffel et al. (2009) "adaptive expertise is not something that can be trained or taught but rather something that has to be promoted or cultivated" (p. 348).

\section{MORE TEACHING EXPERIENCE DOES NOT NECESSARILY LEAD TO BETTER FEEDBACK SKILLS}

Teachers' expertise emerges during the theoretical and practical phases of teacher education and professional experience after university education (Bromme, 2008). It is an open question as to what extent the professional experience of teachers promotes and cultivates adaptive expertise with regard to adequate students' support in individualized lessons. For instance, Christophel (2014) demonstrated that more experienced teachers did not give more appropriate feedback (i.e., feedback that offers phase-specific information) but actually gave more inappropriate feedback than less experienced teachers (e.g., feedback that does not support the task completion but reduces the learner's amount of cognitive resources available for processing the relevant information; Sweller, 2005). Christophel (2014) studied 30 more experienced teachers with a mean professional experience of 11.15 years $(S D=12.85)$ and 30 less experienced teachers with a mean professional experience of 42.07 days $(S D=89.40)$. Teachers watched three video-vignettes of students passing through the different phases of self-regulated learning (goal-setting, performance and the selfreflection phase). The teachers were instructed to stop the films whenever they wanted to give feedback to the students. The results revealed that the more experienced teachers stopped the videovignettes more frequently and more often provided inappropriate feedback to students as compared to their less experienced counterparts. In addition, the study of Baer et al. (2011) showed that professional experience did not lead to better schooling. Baer and colleagues examined the 
development of teacher competences in transition between academic and professional careers. The results demonstrate that teachers with more professional experience did not perform better in the measured aspects of schooling than graduate teachers at the end of their university education.

These findings suggest that professional experience alone is not a good predictor for the progress of teachers' expertise (Baer et al., 2011; cf. Campitelli and Gobet, 2011; Hambrick et al., 2014). Years of teaching are possibly not sufficient to informally and implicitly sensitize most teachers to cues conveying action phases and the matching feedback. This could have diverse reasons. As explained above, school lessons place numerous demands: teachers have to organize and maintain the structure of schooling and can be absorbed by organizational and administrative activities. After university and practical education, there is a lack of peer-coaching (e.g., colleagues who discuss classroom situations) or qualified instruction (e.g., best-practice examples). A lack of (time) resources and motivation to reflect ones feedback behavior might result.

\section{ATTENDING THE LARGER PICTURE}

However, training studies can support an optimistic outlook on the development of teachers' expertise in feedback application. Experienced and inexperienced teachers can be trained to apply feedback that supports realistic goalsetting and adequate self-reflection of learners (Christophel et al., in press). Recommendations helped teachers to increase feedback in line with the motivational phase of the learner from preto post-test while phase-inappropriate feedback could be reduced. Also, attention allocation in the classroom-often a prerequisite for feedback applicationseems to be open to intervention. For instance, Miller (2011; cf. Speelman, 2014; Wiggins et al., 2014) suggested to employ eye-tracking in order to provide (becoming) teachers with feedback on how evenly they distribute their attention across students in the classroom. Students disturbing the setting should not monopolize attention at the cost of other students. While experienced teachers agree that uneven distributions of attention should be avoided, they lack awareness of how well they are yet managing to implement the respective strategies of attention allocation.

\section{REFERENCES}

Baadte, C., and Schnotz, W. (2013). Feedback effects on performance, motivation and mood: are they moderated by the learner's self-concept? Scand. J. Edu. Res. 1-22. doi: 10.1080/00313831.2013. 781059

Baer, M., Kocher, M., Wyss, C., Guldimann, T., Larcher, S., and Dörr, G. (2011). Lehrerbildung und Praxiserfahrung im ersten Berufsjahr und ihre Wirkung auf die Unterrichtskompetenzen von Studierenden und jungen Lehrpersonen im Berufseinstieg. [Teachers'academic career and their professional experience in the first year of their professional career and its impact on their schooling competences]. Zeitschrift für Erziehungswissenschaft, 14, 85-117. doi: 10.1007/s11618-011-0168-5

Bilalić, M., McLeod, P., and Gobet, F. (2008) Inflexibility of experts-reality or myth? Quantifying the Einstellung effect in chess masters. Cogn. Psychol. 56, 73-102. doi: 10.1016/j.cogpsych.2007.02.001

Bilalić, M., McLeod, P., and Gobet, F. (2010). The mechanism of the Einstellung (Set) effect: a pervasive source of cognitive bias. Curr. Dir. Psychol. Sci. 19, 111-115. doi: 10.1177/0963721410363571

Blömeke, S., Eichler, D., and Müller, C. (2003). Rekonstruktion kognitiver Strukturen von Lehrpersonen als Herausforderung für die empirische Unterrichtsforschung. Theoretische und methodologische Überlegungen zu Chancen und Grenzen von Videostudien. [Reconstruction of teachers'cognitive structures as challenge for teaching and learning research. Theoretical and methodological considerations concerning opportunities and limitations of video-studies]. Unterrichtswissenschaft, 31, 103-121. Available online at: http://www.erziehungswissenschaften.huberlin.de/institut/abteilungen/didaktik/data/aufsa etze/2003/Methodologie.empirischer.Unterrichts forschung.pdf

Braitenberg, V. (1984). Vehicles: Experiments in Synthetic Psychology. Cambridge, MA: MIT Press.

Bromme, R. (1997). "Kompetenzen, Funktionen und unterrichtliches Handeln des Lehrers. [Competences, functions and schooling of teachers]," in Enzyklopädie der Psychologie. Psychologie des Unterrichts und der Schule, ed F. E. Weinert (Göttingen: Hogrefe Verlag für Psychologie), 177-212.

Bromme, R. (2008). "Lehrerexpertise. [Teachers'expertise]," in Handbuch der Pädagogischen Psychologie, eds W. Schneider and M. Hasselhorn (Göttingen: Hogrefe), 159-167.

Campitelli, G., and Gobet, F. (2011). Deliberate practice: necessary but not sufficient. Curr. Dir. Psychol. Sci. 20, 280-285. doi: 10.1177/0963721411421922

Christophel, E. (2014). Lehrerfeedback im Individualisierten Unterricht. Spannungsfeld zwischen Instruktion und Autonomie. [Teacher Feedback in Individualized Instruction. Striking the Balance between Instruction and Autonomy]. Wiesbaden: Springer. doi: 10.1007/978-3-658-05099-3

Christophel, E., and Baadte, C. (in press). "Supporting students' self-regulated learning with teachers' feedback: professional experience as a moderator of teachers' attitude-behavior contingency," in Multidisciplinary Research on Teaching and Learning, eds W. Schnotz., A. Kauertz, H. Ludwig, A. Müller, and J. Pretsch (Basingstoke, England: Palgrave Macmillan).

Christophel, E., Baadte, C., Heyne, N., and Schnotz, W. (in press). "Diagnostische und didaktische Kompetenz von Lehrkräften zur Förderung der Text-/Bild-Integrationsfähigkeit bei Schülerinnen und Schülern der Sekundarstufe I (DIKOL). [Diagnostic and didactic competence of teachers in promoting text-picture-integration abilities of student in lower secondary education (DIKOL)]," in Entwicklung von Professionalität pädagogischen Personals. Interdisziplinäre Betrachtungen, Befunde und Perspektiven, eds C. Gräsel and K. Trempler (Wiesbaden: Springer).

Gaschler, R., Katz, D., Grund, M., Frensch, P. A., and Brock, O. (2012). "Intelligent object exploration," in Human Machine Interaction, ed M. Inaki (Rijeka; Shanghai: InTech), 235-260. doi: 10.5772/ 25836

Gobet, F., Snyder, A., Bossomaier, T., and Harré, M. (2014). Designing a "better" brain: insights from experts and savants. Front. Psychol. 5:470. doi: 10.3389/fpsyg.2014.00470

Godau, C., Haider, H., Hansen, S., Schubert, T., and Gaschler, R. (2014). Spontaneously spotting and applying shortcuts in arithmetic - A primary school perspective on expertise. Front. Psychol. 5:556. doi: 10.3389/fpsyg.2014.00556

Gollwitzer, P. M. (1990). "Action phases and mindsets," in Handbook of Motivation and Cognition: foundations of Social Behavior, Vol. 2, eds E. T. Higgins and R. M. Sorrentino (New York, NY: Guilford), 53-92.

Guida, A., Gobet, F., Tardieu, H., and Nicolas, S. (2012). How chunks, retrieval structures and templates offer a cognitive explanation for neuroimaging data on expertise acquisition: a twostage framework. Brain Cogn. 79, 221-244. doi: 10.1016/j.bandc.2012.01.010

Hambrick, D. Z., Oswald, F. L., Altmann, E. M., Meinz, E. J., Gobet, F., and Campitelli, G. (2014). Deliberate practice: is that all it takes to become an expert? Intelligence 45, 34-45. doi: 10.1016/j.intell.2013.04.001

Hatano, G., and Inagaki, K. (1984). Two Courses of Expertise. Research and Clinical Center for Child Development, Annual Report, 6. Available online at: http://hdl.handle.net/2115/25206

Healy, A. F., Kole, J. A., and Bourne, L. E. Jr. (2014). Training principles to advance expertise. Front. Psychol. 5:131. doi: 10.3389/fpsyg.2014.00131

Heckhausen, H., and Gollwitzer, P. M. (1987). Thought contents and cognitive functioning in motivational versus volitional states of mind. Motiv. Emot. 11, 101-120. doi: 10.1007/BF00992338

Lane, P. C. R., Gobet, F., and Cheng, P. C.-H. (2001) What forms the chunks in a subject's performance? Lessons from the CHREST computational model of learning. Behav. Brain Sci. 24, 128-129. doi: 10.1017/S0140525X01363926 
Lerner, R. M., Freund, A. M., De Stefanis, I., and Habermas, T. (2001). Understanding developmental regulation in adolescence: the use of the selection, optimization, and compensation model. Hum. Dev. 44, 29-50. doi: 10.1159/0000 57039

Ley, K., and Young, D. B. (2001). Instructional principles for self-regulation. Educ. Technol. Res. Dev. 49, 93-103. doi: 10.1007/BF02504930

Miller, K. F. (2011). "Situation awareness in teaching - What educators can learn from video-based research in other fields," in Mathematics Teacher Noticing: Seeing through Teachers' Eyes, eds M. Sherin, V. Jacobs, and R. Philipp (New York, NY: Routledge), 51-65.

Narciss, S. (2004). The impact of informative tutoring feedback and self-efficacy on motivation and achievement in concept learning. Exp. Psychol. 51, 214-228. doi: 10.1027/1618-3169. 51.3.214

Rheinberg, F., and Engeser, S. (2010). "Motive training and motivational competence," in Implicit Motives, eds O. C. Schultheiss and J. C. Brunstein (Oxford, England: Oxford University Press), 510-548.

Schmitz, B., and Wiese, B. (2006). New perspectives for the evaluation of training sessions in selfregulated learning: time series-analyses of diary data. Contemp. Educ. Psychol. 31, 64-96. doi: 10.1016/j.cedpsych.2005.02.002
Shulman, L. (1986). Those who understand: knowledge growth in teaching. Educ. Res. 15, 4-14. doi: 10.3102/0013189X015002004

Shulman, L. (1987). Knowledge and teaching: foundations of the new reform. Harv. Educ. Rev. $57,1-22$.

Speelman, C. (2014). The acquisition of expertise in the classroom: Are current models of education appropriate?. Front. Psychol. 5:580. doi: 10.3389/fpsyg.2014.00580

Sweller, J. (2005). "Implications of cognitive load theory for multimedia learning," in The Cambridge Handbook of Multimedia Learning, ed R. E. Mayer (New York, NY: Cambridge University Press), 19-30.

Verschaffel, L., Luwel, K., Torbeyns, J., and Van Dooren, W. (2009). Conceptualizing, investigating, and enhancing adaptive expertise in elementary mathematics education. Eur. J. Psychol. Educ. 24, 335-359. doi: 10.1007/BF03174765

Visser, U., and Burkhard, H. D. (2007). RoboCup 10 years of achievements and future challenges. AI Magazine 28, 115-132. doi: 10.1609/aimag.v28i2. 2044

Wiggins, M., Brouwers, S., Davies, J., and Loveday, T. (2014). Trait-based cue utilization and initial skill acquisition: implications for models of the progression to expertise. Front. Psychol. 5:541. doi: 10.3389/fpsyg.2014.00541
Zimmerman, B. J. (2000). "Attaining self-regulation. A social cognitive perspective," in Handbook of Self-Regulation, eds M. Boekaerts, P. R. Pintrich, and M. Zeidner (San Diego, CA: Academic Press), 13-39.

Conflict of Interest Statement: The authors declare that the research was conducted in the absence of any commercial or financial relationships that could be construed as a potential conflict of interest.

Received: 30 May 2014; accepted: 19 July 2014; published online: 05 August 2014.

Citation: Christophel E, Gaschler $R$ and Schnotz W (2014) Teachers' expertise in feedback application adapted to the phases of the learning process. Front. Psychol. 5:858. doi: 10.3389/fpsyg.2014.00858

This article was submitted to Cognition, a section of the journal Frontiers in Psychology.

Copyright (C) 2014 Christophel, Gaschler and Schnotz. This is an open-access article distributed under the terms of the Creative Commons Attribution License (CC BY). The use, distribution or reproduction in other forums is permitted, provided the original author(s) or licensor are credited and that the original publication in this journal is cited, in accordance with accepted academic practice. No use, distribution or reproduction is permitted which does not comply with these terms. 